\title{
A QUANTUM MECHANICAL STUDY OF STRUCTURAL AND ELECTRONIC DILUTION EFFECTS IN PARAMAGNETIC CHEMICAL EXCHANGE SATURATION TRANSFER AGENTS
}

\author{
${ }^{1,2}$ Whelton A. Miller III and ${ }^{2}$ Preston B. Moore \\ ${ }^{1}$ Department of Bioengineering, University of Pennsylvania, Philadelphia, PA 19104, USA \\ ${ }^{2}$ Department of Chemistry and Biochemsitry, West Center for Computational Chemistry and Drug Design, \\ University of the Sciences in Philadelphia, Philadelphia, PA 19104, USA
}

Received 2012-12-22; Revised 2013-12-10; Accepted 2013-12-11

\begin{abstract}
We present a computational study of the effect of chemical modifications of the meta and para substituents in the coordinating pendant arm of a modified 1,4,7,10-tetraazacyclododecane-N, N', N', N', 'tetraamide (DOTAM) ligand on the Chemical Exchange Saturation Transfer (CEST) signal. Magnetic Resonance Imaging (MRI) is currently one of the most widely used techniques available. MRI has led to a new class of pharmaceuticals termed "imagining" or "contrast" agents. These agents usually work by incorporating lanthanide metals such as Gadolinium (Gd) and Europium (Eu). This allows the contrast agents to take advantage of the paramagnetic properties of the metals, which in turn enhances the signal detectable by MRI. The effect of simple electron-withdrawing (e.g., nitro) and electron-donating (e.g., methyl) substituents chemically attached to a modified chelate arm (pendant arm) is quantified by charge transfer interactions in the coordinated water-chelate system computed from quantum mechanics. This study attempts to reveal the origin of the substituent effect on the CEST signal and the electronic structure of the complex. We find that the extent of Charge Transfer (CT) depends on orbital orientations and overlaps. However, CT interactions occur simultaneously from all arms, which causes a dilution effect with respect to the pendant arm.
\end{abstract}

Keywords: Magnetic Resonance Imaging, Contrast Agent, DOTAM, PARACEST

\section{INTRODUCTION}

Magnetic Resonance Imaging (MRI) is a noninvasive tool used by the medical community to diagnose disease. Imaging agents, usually chelates, are used to enhance MRI signals. Our study focuses on the physical basis of MRI signal enhancement induced by chemical modifications of a novel class of Paramagnetic Chemical Exchange Saturation Transfer (PARACEST) agents (Lauffer, 1987; Caravan et al., 1999; Woods et al., 2009). With these agents, the magnetic resonance image is modified by magnetization transfer between the water molecule bound to the M (III)(DOTAM) chelate and bulk water, which is inversely proportional to the rate of water exchange between the bound and bulk water. The water exchange rate depends on the size, the coordination geometry of the metal ion and the electronic properties of the groups attached to the coordinating pendant arm. Typically lanthanide ions, such as $\mathrm{Gd}$ and $\mathrm{Eu}$, are used because of their paramagnetic properties. However, because of the insensitivity of f-electrons to their environment, we can use d-orbital transition metals to approximate effects of these lanthanide ions. This approximation reduces computational effort while giving rise to satisfactory results for structure and bonding (Furet et al., 2008).

Corresponding Author: Preston B. Moore, Department of Chemistry and Biochemsitry, West Center for Computational Chemistry and Drug Design, University of the Sciences in Philadelphia, Philadelphia, PA 19104, USA 
1,4,7,10-tetraazacyclododecane-1,4,7,10-tetraacetic acid (DOTA) and DOTA-like derivatives typically exist in two diasteriomeric forms, m-Twisted Square Antiprism (TSA) and M-Square Antiprism (SA), which differ by the rotation of their corresponding acetate arms (Aime et al., 1994). The two diasteriomers come from the orientation of the two square planes formed by the four nitrogens and four oxygens coordinating the metal ion. These arrangements appear common to all DOTA-like ligrands, such as the 1,4,7,10-tetraazacyclododecane$\mathrm{N}, \mathrm{N}, \mathrm{N}, \mathrm{N}$-tetraamide (DOTAM) considered in this work. For $\mathrm{M}(\mathrm{III})(\mathrm{DOT} A \mathrm{M})$ complexes, in the case of $[\mathrm{Eu}(\mathrm{III})(\mathrm{DOTAM})(\mathrm{H} 2 \mathrm{O})]$, an m-type structure has been found (Woods et al., 2003).

It is important to understand the relationship between the bound and bulk water with contrast agents. By investigating the role of electronics and CT interactions, we hope to combine this with the results from current literature to further the knowledge of ligand design. The goal of this study is to understand the electronic structure effect of modifying DOTAM with a phenyl pendant arm (Fig. 1). The pendant arm is substitued with various substiuents ranging from electron donating to electron withdrawing, e.g., p/m$\mathrm{OCH}_{3}, \mathrm{p} / \mathrm{m}-\mathrm{CH}_{3}, \mathrm{p} / \mathrm{m}-\mathrm{F}, \mathrm{p} / \mathrm{m}-\mathrm{CN}$. We hypothesized that electron-donating substiuents would push the electron density from the pendant benzene through the coordinating amide and onto the central metal ion. This would weaken the metal-water interaction and accelerate water exchange. Conversely, electronwithdrawing groups were expected to decelerate water exchange by pulling electron density from the coordinating amide and strengthening the metal-water bond. Here, we used computational methods to understand the interactions between the central M(III) ion and exchangeable water molecules to compare the interactions across the complexes with different pendant arms.

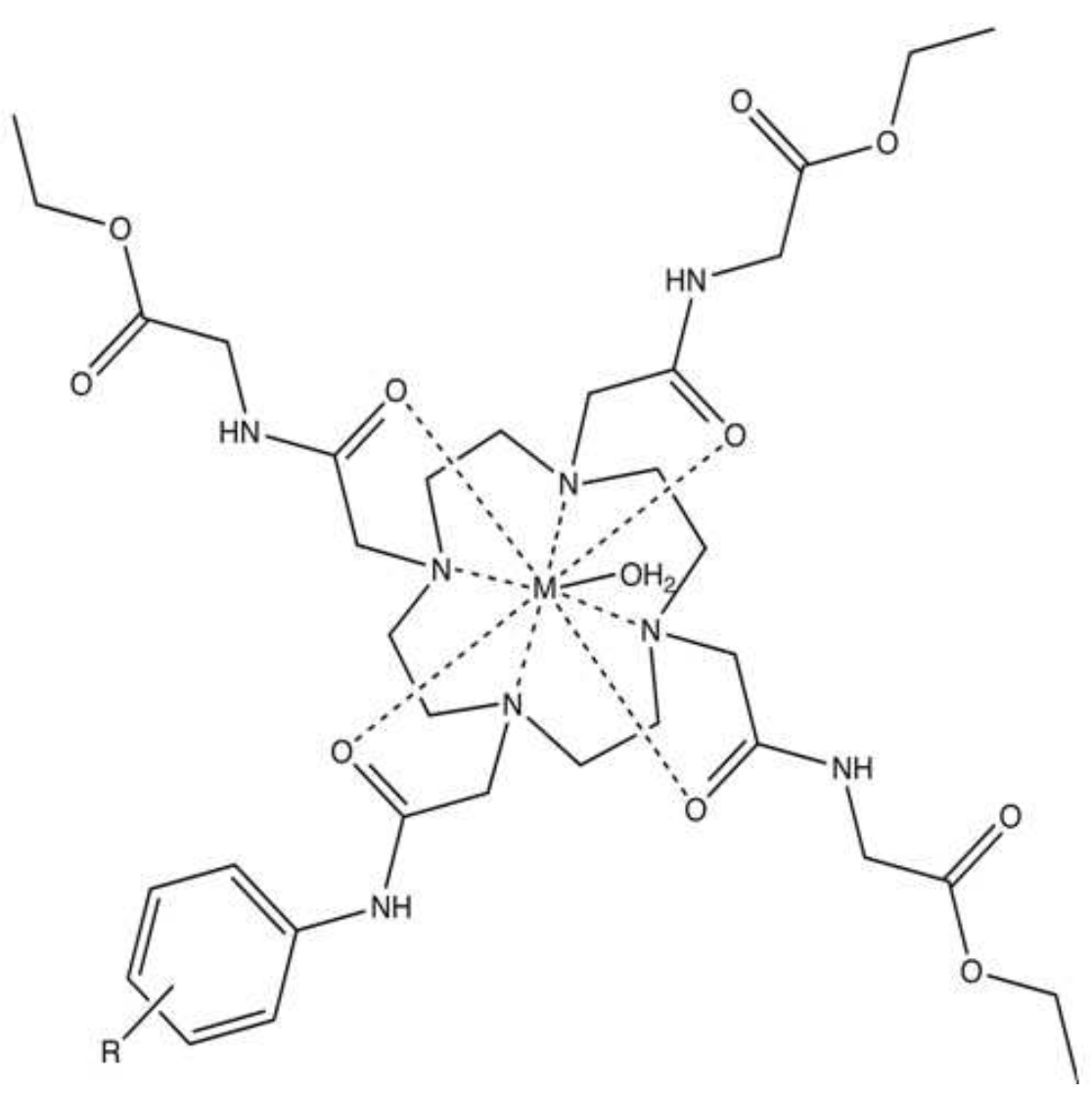

Fig. 1. General Structure of modified ligand with pendant arm 


\section{MATERIALS AND METHODS}

\subsection{Methodology}

The starting geometry was obtained by substituting $\mathrm{Eu}(\mathrm{III})$ with $\mathrm{Y}$ (III) and Sc(III) in the X-ray structure of the Eu(DOTAM) complex (Aime et al., 1999a). Y(III) has approximately the same size, charge and coordination as $\mathrm{Gd}(\mathrm{III})$ and $\mathrm{Eu}(\mathrm{III})$ and is considered a pseudo-lanthanide. $\mathrm{Sc}(\mathrm{III})$ was used to support and compare the results from the Y(III) complexes. The geometry was optimized using Density Functional Theory (DFT), at the B3LYP (Becke, 1993; Lee et al., 1988) Level. Basis sets used were: LANL2DZ (Wadt and Hay, 1985; Hay and Wadt, 1985a; 1985b) and DGDZVP (Yurieva et al., 2008; Dunning and Huzinaga, 1976). Analysis of results was performed using Natural Bond Orbital Theory (Reed et al., 1988; Weinhold, 1998). Calculations were carried out by Gaussian03 (Frisch, 2004) and NBO (Aime et al., 1994; Glendening et al., 2001). Software packages. Literature results were used to compare and verify the calculated Y(III) and Sc(III) structures with experimental data (Lau et al., 2006; Kotex et al., 2006; Benetollo et al., 2003; Muller et al., 2002; Kumar et al., 1994; Parker et al., 2003).

\subsection{Hammett Constants}

To compare the effects of different substituents attached to the pendant benzene, Hammett Constants were used to standardize the relationship between substituents and CT interactions. Hammett Constants were developed by Hammett (1937) and are commonly used in organic chemistry to describe the relationship between reaction rates and equilibrium constants for many reactions involving benzoic acid and benzoic acid-like derivatives with meta or para substituents. These constants are specific for aromatic reactions differing by the type of substituent; however, they are not limited to benzoic acid (Gross and Seybold, 2001; Pratt et al., 2004; Ilieva et al., 2002).

Typically, Hammett Constant interactions work by two methods, induction and resonance. Induction interactions take place through the sigma $(\sigma)$ bond system and generally rely on the electronegativity properties of the substituent. Resonance interactions occur through the pi $(\pi)$ system and take advantage of the delocalized electrons in the benzene ring (Sinnokrot and Sherrill, 2003; Campanelli et al., 2003), which, for example, can interact with atoms with lone-pair electrons (Gung et al., 2008). The location and structure of the pendant benzene is designed to take advantage of both induction and resonance interactions from the benzene ring. This effect on the $\pi$-system in particular, will depend on the category of the substituent as well as its location at either the meta or para positions. The effect of the substituent is transmitted through the conjugated $\pi$-system, which will in turn affect the charge of the coordinating oxygen. This change can be quantified by the relationship of the substituent to its Hammett Constant (Hollingsworth et al., 2002). The relationship between the Hammett Constant $(\sigma)$ and the charge of the oxygen on the pendant arm should be linear. As the $\sigma$-value increases, denoting an Electron-Withdrawing Group (EWG), the charge on the oxygen should become more positive. As the $\sigma$-value decreases, denoting an Electron-Donating Group (EDG) the charge on the oxygen should become more negative. No substituent $(\mathrm{H})$, has a Hammett Constant of $(0.0)$ and will represent neither an increase nor decrease in the charge of the coordinating oxygen. Because of the associated change in charge as a result of shielding and deshielding with respect to the substituent, the relationship between the Hammett Constant and charge can also be tracked via NMR (Elango et al., 2005).

\section{RESULTS}

\subsection{Structure of Arms}

To quantify the relationship of the pendant arm substituent with the charge on the chelating oxygen, the pendant arm was separated from the compound (Fig. 2). The resulting compound was then optimized using the DFT/dgdzvp level of theory. The carbonyl oxygen charge was examined using Natural Population Analysis. The chelating oxygen charge was found to be in good correlation with the Hammett Constant and gave a good linear fit with respect to the Hammett Constant, as expected (Fig. 3). This showed that CT interactions were indeed being transmitted from the pendant benzene to the coordinating oxygen.

\subsection{Structure of Modified M(III)(DOTAM) Complex}

The DOTAM consists of a coordination section between the carbonyl oxygen and the capping nitrogen (Fig. 2 and 4), separated by a methylene group $\left(\mathrm{CH}_{2}\right)$. The tail end of the structure consists of an ethyl acetate group for 3 out of 4 arms. The modified portion of the complex, the "pendant group," consists of benzene with various electron-donating or electron-withdrawing groups substituted at the meta or para position with respect to the amide group (Fig. 2 and 4 ). 
Whelton A. Miller III and Preston B. Moore / Journal of Organic and Biomolecular Simulations 1 (1): 1-13, 2014
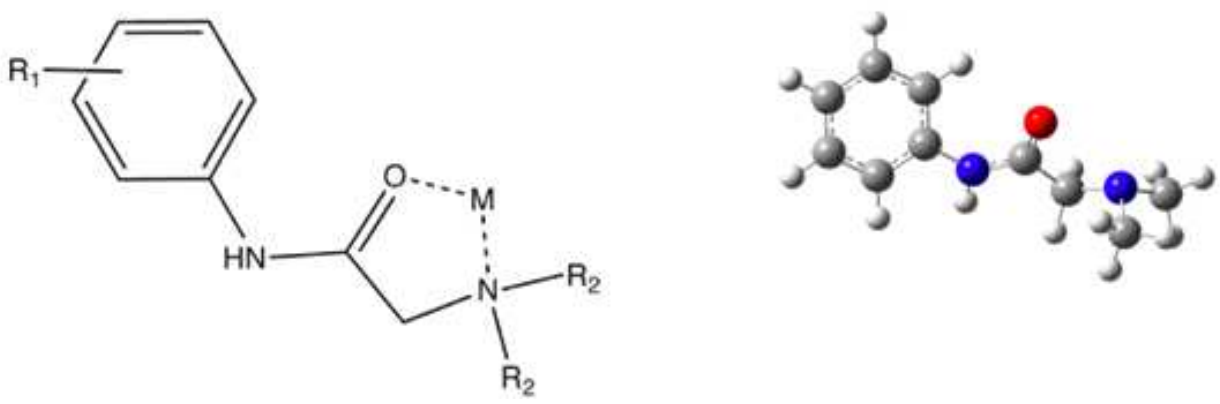

Fig. 2. Coordination scheme for pendant arm structure and for clarity, pendant arm structure shown in ball and stick model: red, oxygen; grey, carbon; white, hydrogen; dark blue, nitrogen

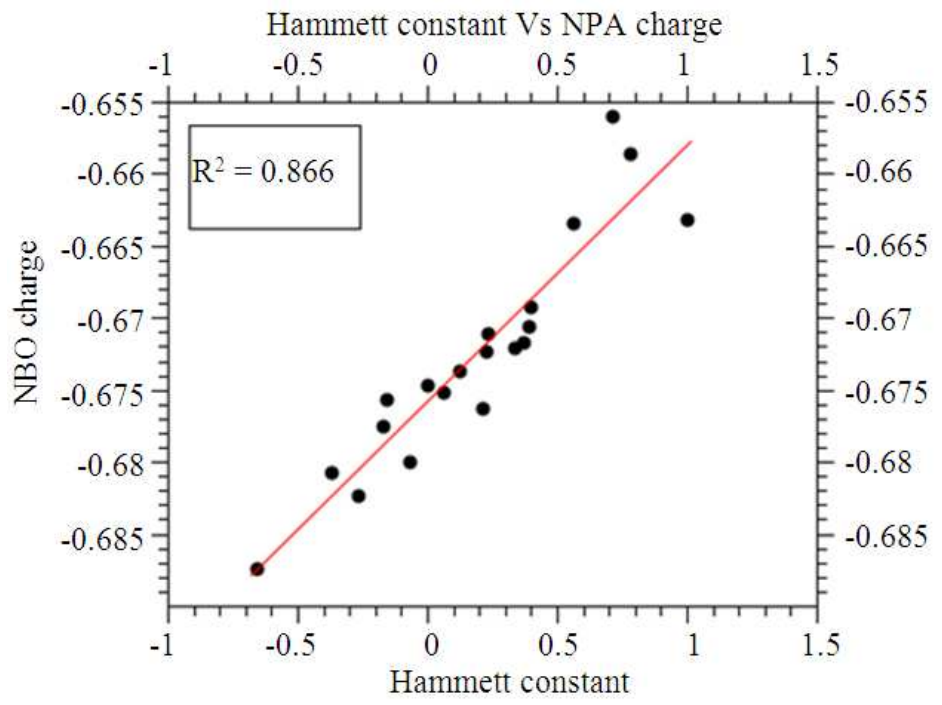

Fig. 3. Charge distributions for pendant arm (separated from the complex) with relation to Hammett Constant ( $\sigma$ ) Left, Natural Population Analysis (NPA)
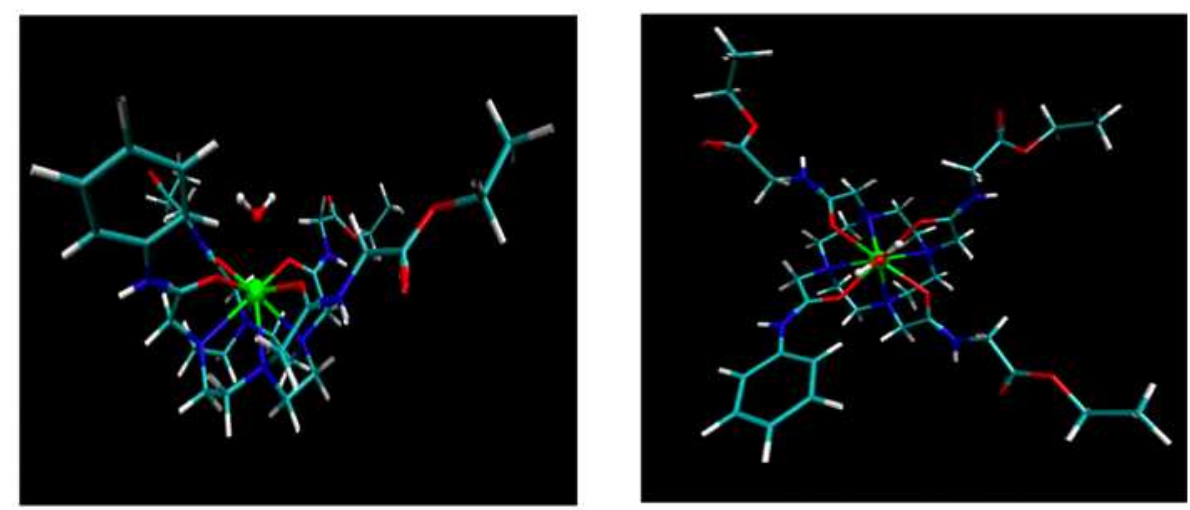

Fig. 4. Left: side view; right: top view. For clarity, complex structure shown in stick model, exchangeable water in ball and stick model. Green, yttrium; red, oxygen; blue, carbon; white, hydrogen; dark blue, nitrogen 
Whelton A. Miller III and Preston B. Moore / Journal of Organic and Biomolecular Simulations 1 (1): 1-13, 2014

The structures of complexes were optimized, all with coordinated water to $\mathrm{M}(\mathrm{III})$ and without coordinated water to M(III). Of the two conformations (Square Anti-Prism (SAP) and Twisted Square AntiPrism (TSAP)), the optimized structure in most cases resembles the TSAP conformation, agreeing with experimentally derived geometries of related Sc and Y complexes (Lau et al., 2006; Kotex et al., 2006; Benetollo et al., 2003; Muller et al., 2002; Kumar et al., 1994; Parker et al., 2003).

The extent of CT depends on orbital orientations and overlaps empty $\mathrm{Sc}(\mathrm{III})$ and Y(III) orbitals (3d and $4 \mathrm{~d}$ respectively), as well as the lone pairs of the carbonyl oxygen atom of the variable arm. Water will undergo a slight conformation change once bonded to the metal ion. This change, described by Water Perturbation Energy (WPE), can be calculated using Equation 1. This conformational change is the difference between unbound water and water bound to the ligand. The shift after binding is small, ranging from $0.03 \mathrm{kcal} \mathrm{moL}^{-1}$ for scandium and $0.10 \mathrm{kcal} \mathrm{moL}^{-1}$ for yttrium. However small, this change in conformation could result in proton shift, which could account for changes in exchange rate (Caravan et al., 2003; Aime et al., 1999b) and thus affect the MRI contrast:

$[$ water $($ optimized $)]-[$ water $($ ligand $)]$
$=[$ Water Perturbation Energy $]($ WPE $)$

\subsection{Ligand Perturbation and Charge Transfer Interactions}

Upon binding, the ligand shifts conformation (Consentino et al., 2004; Stoppioni and Vaira, 2002), which is described by the Ligand Perturbation Energy (LPE). This conformational shift is substantial and much larger when compared to WPE. The LPE can be calculated using Equation 2. Table 1 shows that for scandium the LPE ranges from 7-12 $\mathrm{kcal} \mathrm{moL}^{-1}$, which is approximately the same amount of energy as the metalwater bond discussed later in this study. For yttrium, there is also a significant amount of energy that goes into the LPE, ranging from 3-8 $\mathrm{kcal} \mathrm{moL}^{-1}$. Based on these results, we can see that the amount of perturbation in both the ligand and water is highly dependent on the metal ion (Zhang et al., 2002):

$$
\begin{aligned}
& {[\text { Ligand }- \text { water }(\text { optimized })]-[\text { water }(\text { ligand })]} \\
& -[\text { Ligand }- \text { no }- \text { water }(\text { optimized })] \\
& -[\text { energy of water conformation change }] \\
& =[\text { Ligand Perturbation Energy }](\text { LPE })
\end{aligned}
$$

Table 1. Amount of work $(\mathrm{kcal} / \mathrm{mol})$ involved in the conformation shift of the DOTAM ligand after water attached

\begin{tabular}{lcl}
\hline $\begin{array}{l}\text { Substituent } \\
(\sigma-\mathrm{value})\end{array}$ & $\begin{array}{l}\text { Ligand perturbation } \\
\text { energy }(\mathrm{Sc}) \mathrm{kcal} / \mathrm{mol}\end{array}$ & $\begin{array}{l}\text { Ligand perturbation } \\
\text { energy (Y) kcal/mol }\end{array}$ \\
\hline pCH3 (-0.17) & 8.74 & 3.53 \\
$\mathrm{pCN}(1.0)$ & 7.88 & 3.72 \\
$\mathrm{pF}(0.062)$ & 8.02 & 3.45 \\
$\mathrm{H}(0.0)$ & 8.62 & 3.49 \\
$\mathrm{pNO} 2(0.778)$ & 8.68 & 3.56 \\
$\mathrm{pOCH}(-0.268)$ & 11.80 & 3.55 \\
$\mathrm{pBr}(0.232)$ & 7.94 & 3.46 \\
$\mathrm{pCl}(0.227)$ & 9.93 & 3.46 \\
$\mathrm{mBr}(0.391)$ & 8.57 & 3.96 \\
$\mathrm{mCH}(-0.069)$ & 9.25 & 3.94 \\
$\mathrm{mCl}(0.373)$ & 10.18 & 3.91 \\
$\mathrm{mCN}(0.56)$ & 8.48 & 3.77 \\
$\mathrm{mF}(0.337)$ & 7.98 & 3.87 \\
$\mathrm{mNO} 2(0.71)$ & 10.49 & 7.62 \\
$\mathrm{mOCH} 3(-0.16)$ & 9.87 & 3.89 \\
\hline
\end{tabular}

\subsection{Charge of Coordinating Oxygens}

The respective charges of the coordinating oxygens were anlyazed by Natural Population Analysis (NPA). The effect on the coordinating oxygen should be described by a linear relationship similar to the pendant arm discussed earlier. Emphasis is on the pendant arm oxygen (oxygen 5 and 4) for yttrium and scandium respectively (Fig. 5). These data show that the oxygen charge is affected by the substituent on the pendant arm (Fig. 6-8). However, that effect is not as pronounced as the effects on individual, isolated arms. This "dilution effect" is a result of conformational shifts, quantified by the LPE, and is enhanced due to steric hindrance from other portions of the ligand. These effects interfere with proper alignment of the pendant arm to give optimal orbital overlap. The reduction in proper orbital overlap also reduces the amount of charge that can be transferred from the pendant arm via resonance, or by induction into the chelating oxygen. As a result of dilution effects, the charge transmitted from the pendant arm is partially lost.

\subsection{Electronic Dilution of Adjacent Arms}

Although the target coordinating oxygen does show an effect on charge transmitted from the attached substituent, that effect is compensated by the remaining attached arms. This in turn "scatters" the effect of the CT interactions. Therefore, the water oxygen M-bond is affected by the reduction or gain of charge, but this effect is relatively dilute with respect to the independent charge located on the pendant oxygen. 

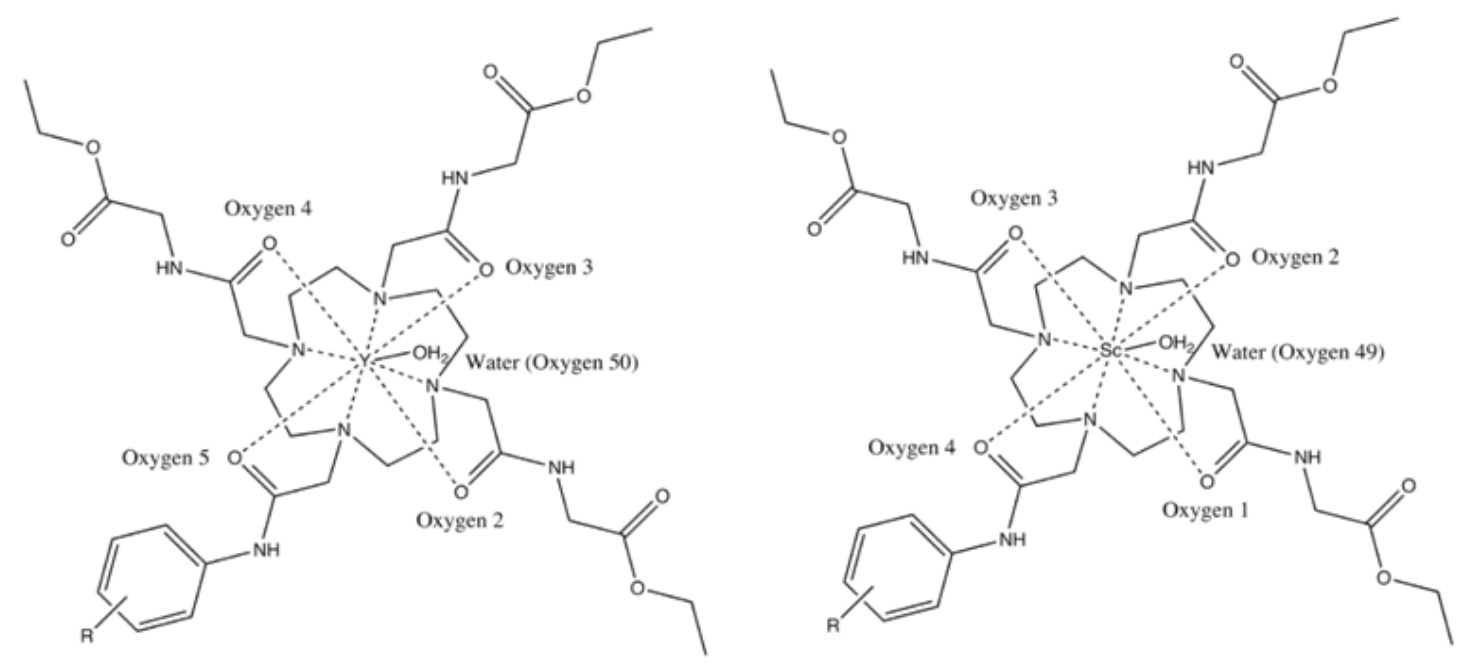

Fig. 5. General structure of modified Yttrium(III)(DOTAM) complexes General structure of modified Scandium(III)(DOTAM) complexes
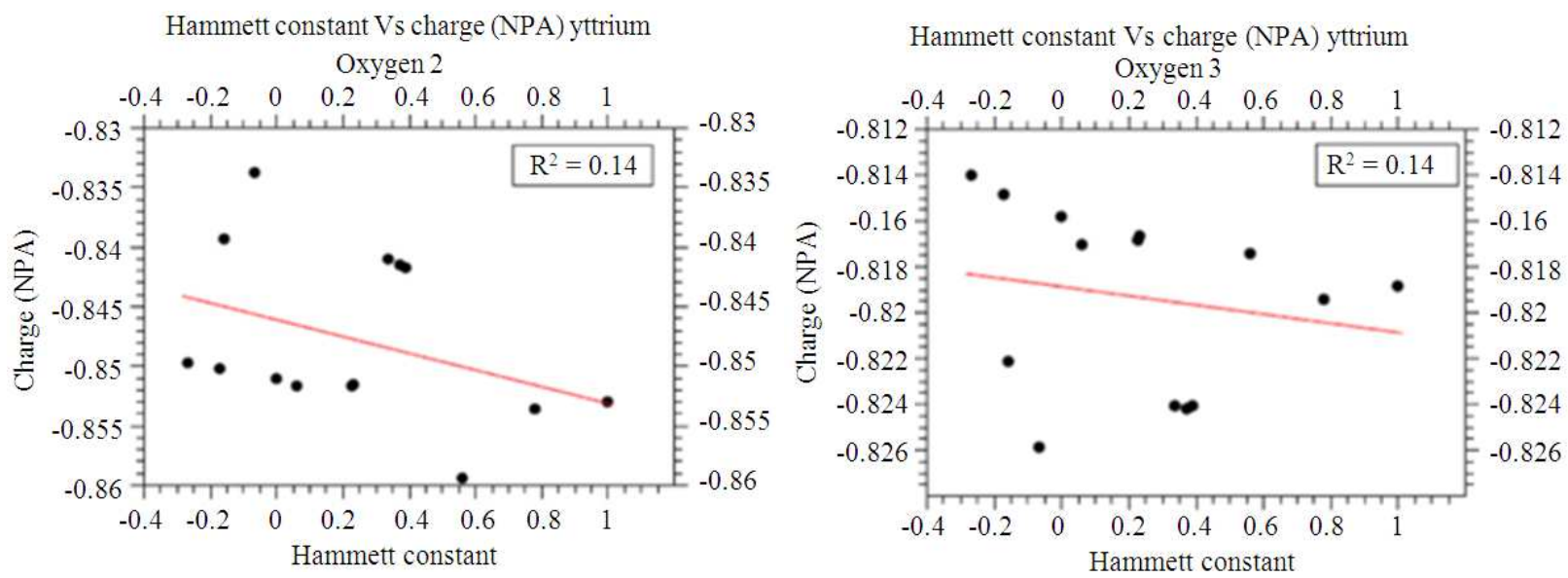

Hammett constant Vs charge (NPA) yttrium Oxygen 4
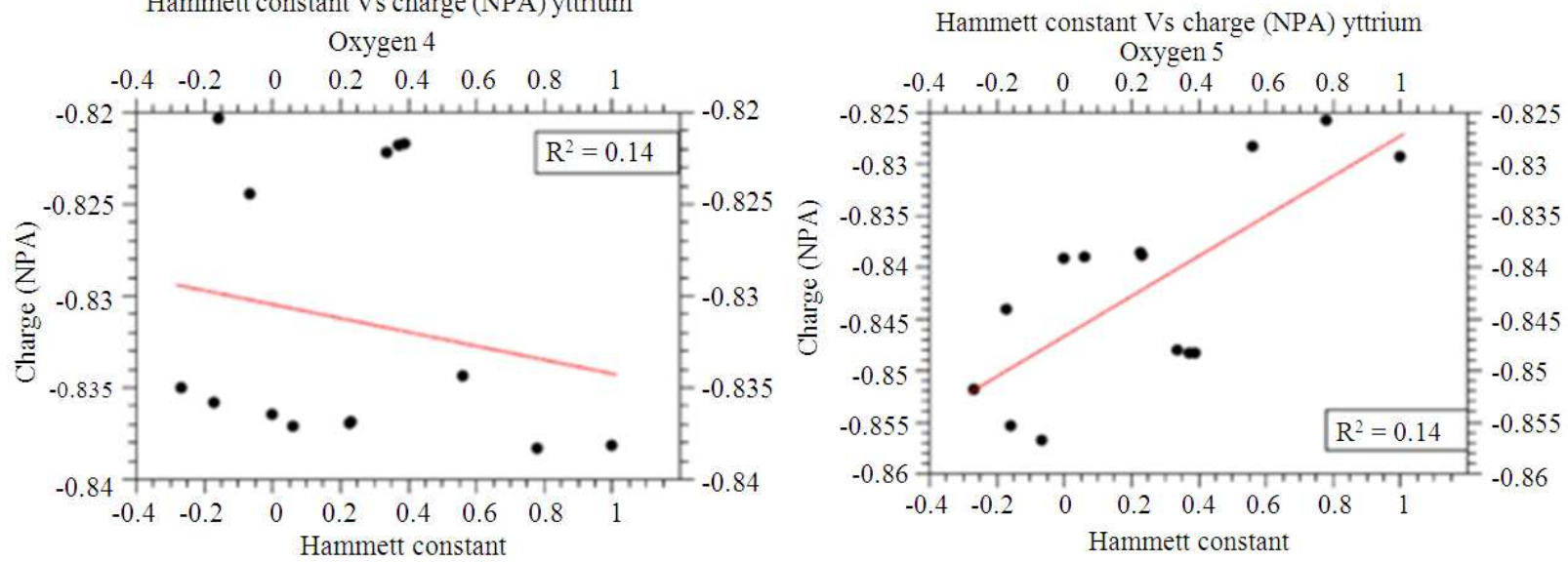

Fig. 6. Natural Population Analysis (NPA) charge distributions with relation to Hammett Constant $(\sigma)$ of all four coordinating oxygens in the yttrium compounds. Pendant arm oxygen is Oxygen 5. 
Whelton A. Miller III and Preston B. Moore / Journal of Organic and Biomolecular Simulations 1 (1): 1-13, 2014
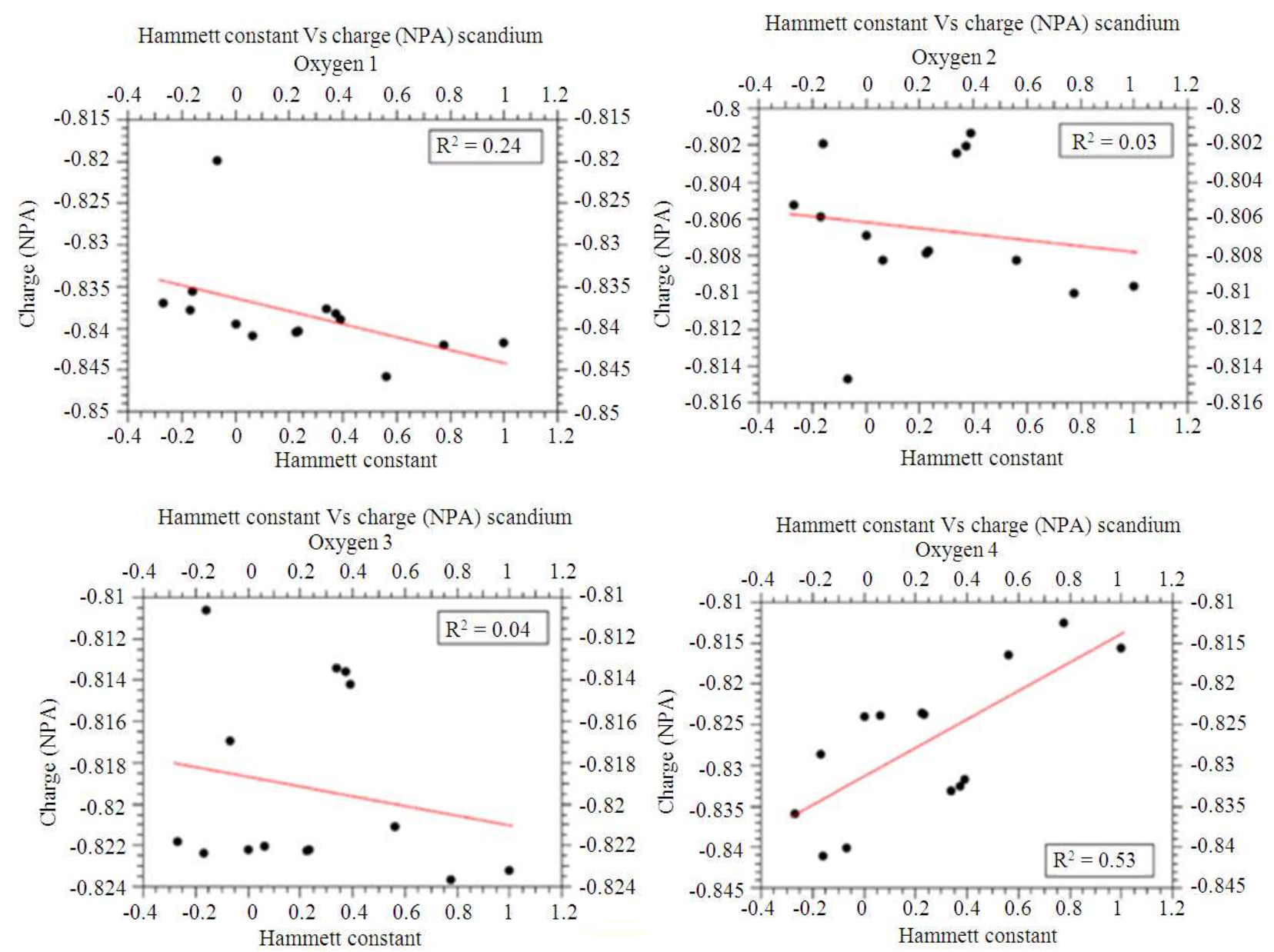

Fig. 7. Natural Population Analysis (NPA) charge distributions with relation to Hammett Constant $(\sigma)$ of all four coordinating oxygens in the Scandium compounds. Pendant arm oxygen is Oxygen 4.
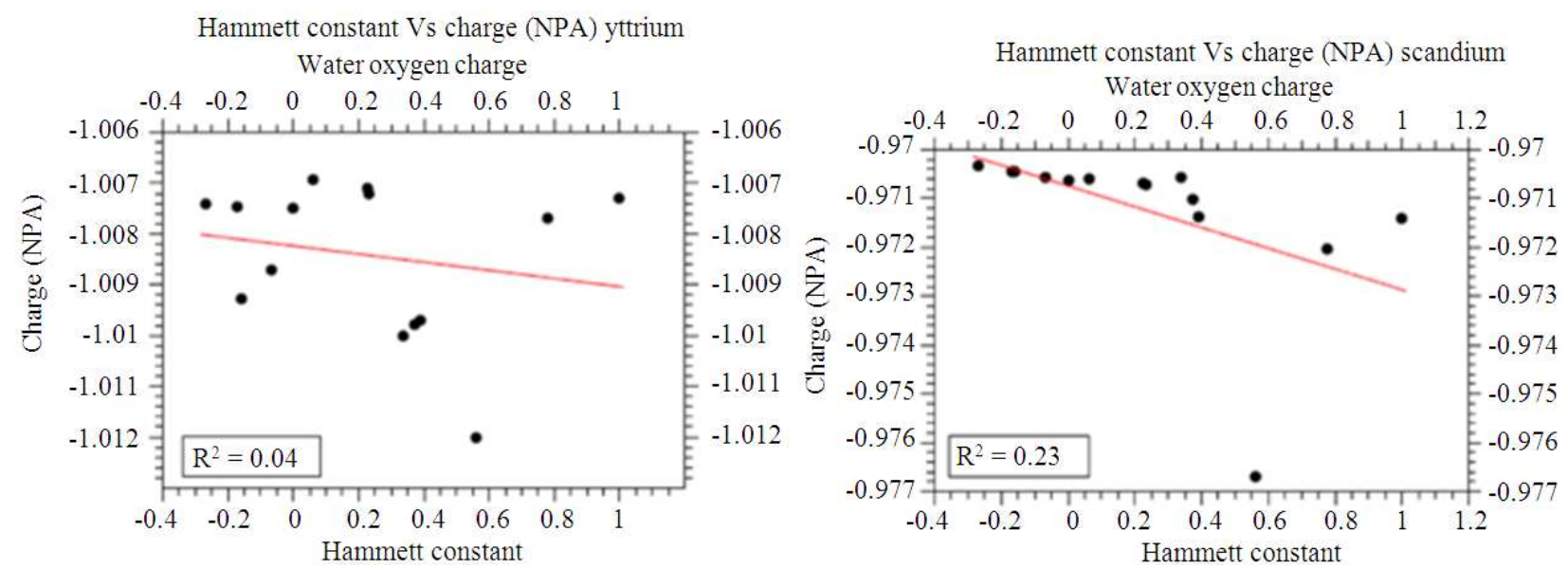

Fig. 8. Charge distributions (NPA) with relation to Hammett Constant $(\sigma)$ on water oxygen for yttrium and scandium 


\subsection{NBO Analysis of M(III)(DOTAM) Complexes}

Within the NBO framework, analysis was done on the Charge Transfer (CT) interactions between nearly empty $\mathrm{Sc}(\mathrm{III})$ and $\mathrm{Y}(\mathrm{III})$ orbitals $(3 \mathrm{~d}$ and $4 \mathrm{~d}$ respectively) and the donating bond and lone pair NBOs of the carbonyl oxygen atom of the variable arm. The extent of CT depends on orbital orientations and overlaps. Although there is a difference between CT interactions among various substituents, Table 2 shows that the difference in transfer of energy $(\mathrm{kcal} / \mathrm{mol})$ from the Lone Pairs (LPs) of the chelating oxygens into the Lone Pair * $\left(\mathrm{LP}^{*}\right)$ orbitals of the central metal ions are not

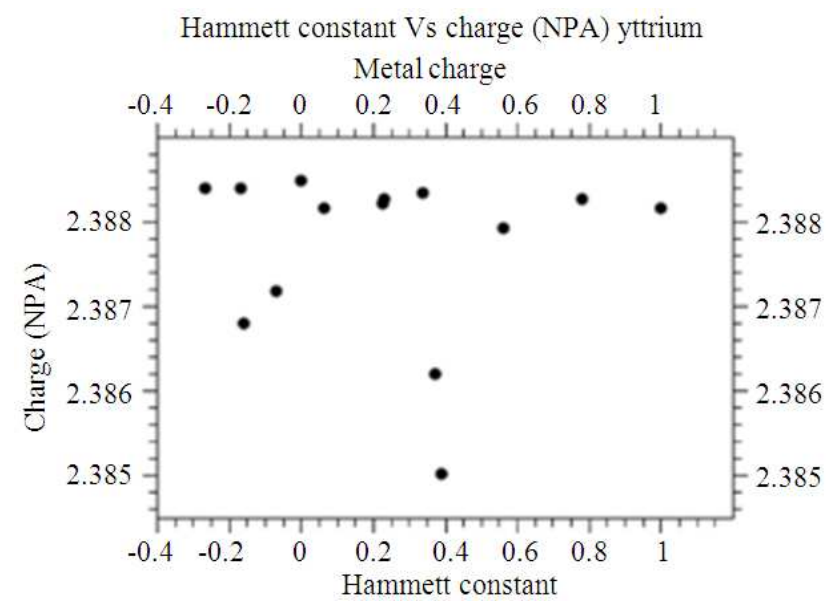

in conjunction with the relationship to the Hammett Constants. This corresponds to the charge analysis observed in the previous sections, which indicates that CT interactions are almost independent of the substituent. The oxygens from adjacent arms are compensating for the differences in charges in the system.

The chelated metal also compensates for an increase or loss of charge from the pendant or oxygen with charge transfer from the other 3 chelating oxygens. This negates the effect of the substituent on the pendant arm of the complex. Overall, these results highlighs the dilution effect mentioned earlier (Fig. 9 and 10).

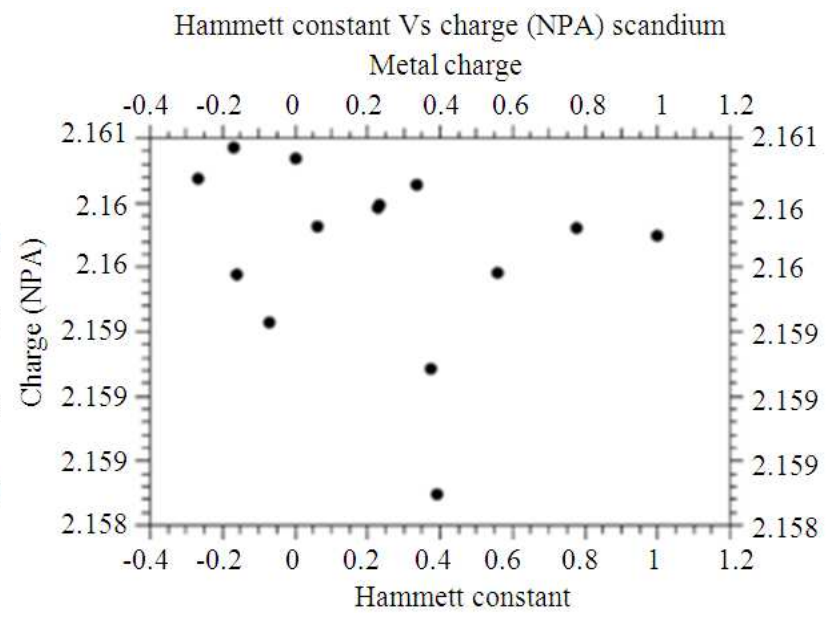

Fig. 9. Charge distributions (NPA) with relation to Hammett Constant ( $\sigma)$ on M(III) ion (yttrium and scandium)
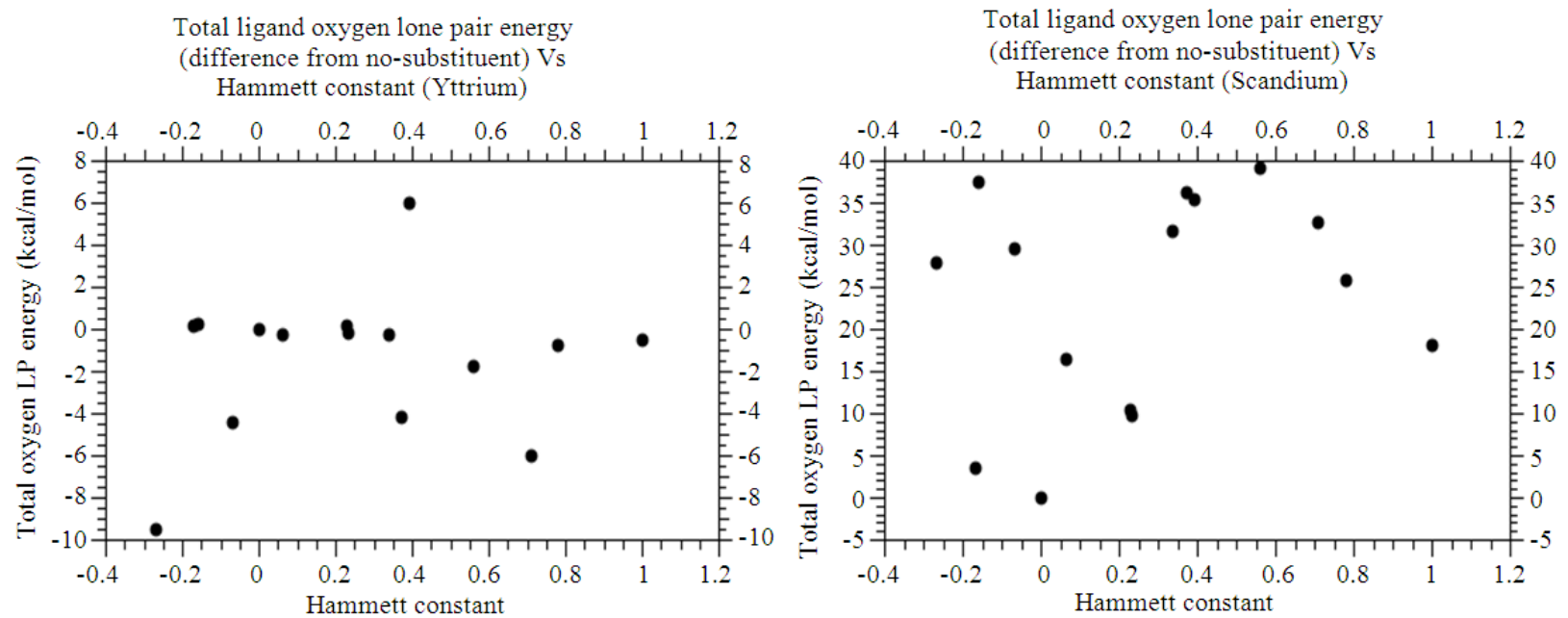

Fig. 10. Change in ligand LP to Metal energy with relation to Hammett Constant $(\sigma)$ on M(III) ion (yttrium and scandium) 

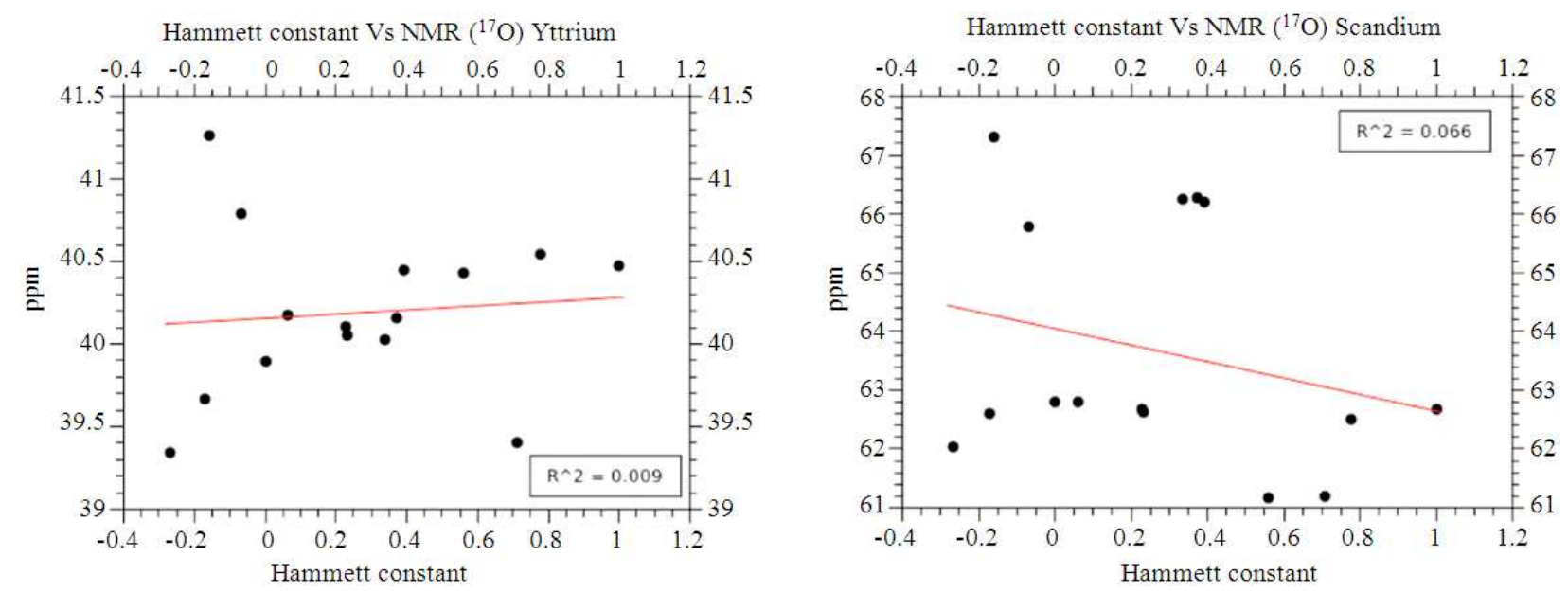

Fig. 11. Calculated Isotropic ${ }^{17} \mathrm{O}$ NMR of bound water with relation to Hammett Constant $(\sigma)$ on $\mathrm{M}(\mathrm{III})$ ion (yttrium and scandium)

Table 2. Occupancy total energy $(\mathrm{kcal} / \mathrm{mol})$ from oxygen Lone Pairs (LP) into scandium and yttrium LP* based on substituent.

\begin{tabular}{llccr}
\hline Substituent $(\sigma)$ & $\begin{array}{l}\mathrm{O}(\mathrm{LP}) \text { to } \mathrm{M}(\mathrm{LP} *) \\
(\mathrm{Sc}) \mathrm{kcal} / \mathrm{mol}\end{array}$ & $\begin{array}{l}\Delta \text { from }(\mathrm{H}) \\
\mathrm{kcal} / \mathrm{mol}\end{array}$ & $\begin{array}{l}\mathrm{O}(\mathrm{LP})->\mathrm{M}(\mathrm{LP} *) \\
(\mathrm{Y}) \mathrm{kcal} / \mathrm{mol}\end{array}$ & $\begin{array}{r}\Delta \text { from }(\mathrm{H}) \\
\mathrm{kcal} / \mathrm{mol}\end{array}$ \\
\hline $\mathrm{pCH}(-0.17)$ & 146.6 & 3.50 & 140.9 & 0.16 \\
$\mathrm{pCN}(1.0)$ & 161.2 & 18.10 & 140.2 & -0.53 \\
$\mathrm{pF}(0.062)$ & 159.5 & 16.40 & 140.4 & -0.26 \\
$\mathrm{H}(0.0)$ & 143.0 & 0.00 & 140.7 & 0.00 \\
$\mathrm{pNO}_{2}(0.778)$ & 168.8 & 25.70 & 139.9 & -0.77 \\
$\mathrm{pOCH}(-0.268)$ & 170.9 & 27.80 & 131.2 & -9.46 \\
$\mathrm{pBr}(0.232)$ & 152.8 & 9.80 & 140.5 & -0.20 \\
$\mathrm{pCl}(0.227)$ & 153.4 & 10.34 & 140.9 & 0.19 \\
$\mathrm{mBr}(0.391)$ & 178.4 & 35.38 & 146.7 & 6.02 \\
$\mathrm{mCH}(-0.069)$ & 172.6 & 29.56 & 136.2 & -4.45 \\
$\mathrm{mCl}(0.373)$ & 179.3 & 36.29 & 136.5 & -4.15 \\
$\mathrm{mCN}(0.56)$ & 182.1 & 39.10 & 138.9 & -1.79 \\
$\mathrm{mF}(0.337)_{\mathrm{mNO}_{2}(0.71)}$ & 174.7 & 31.64 & 140.5 & -0.24 \\
$\mathrm{mOCH}_{3}(-0.16)$ & 175.6 & 32.61 & 134.7 & -5.96 \\
\hline
\end{tabular}

\section{DISSCUSION}

\subsection{Water-Metal Bond Strength}

The bond strength between water and the central metal is partially affected by the CT interactions resulting from the pendant arm. Bond strength is also highly dependent on the geometry of the ligand, resulting from steric interactions and electronic effects from all chelating oxygens. The Metal-Water Bond Strength (MWBS), can be calculated using Equation 3. The LPE (Equation 2 and Table 1), can then be removed to highlight the effect of the ligand conformational shift on the metal-water bond. The ligand conformational shift, which takes place after the water is bound, enhances the strength of the metalwater bond (Table 3). The overall metal-water bond strength, although affected by the electronics from the pendant arm, does not correlate well with respect to the Hammett Constant (Table 3):

\footnotetext{
[Ligand - water (optimized) $]-[$ water(ligand) $]$$$
\text { -energy of water conformation change] }
$$$$
\text { -[Ligand - water removed) }
$$$$
[=\{\text { Metal }- \text { Water Bond Strength }](\text { MWBS })
$$ 
Whelton A. Miller III and Preston B. Moore / Journal of Organic and Biomolecular Simulations 1 (1): 1-13, 2014

Table 3. Water oxygen-metal bound strength $\mathrm{kcal} / \mathrm{mol}$ for both scandium and yttrium

\begin{tabular}{lllll}
\hline Substituent $(\sigma$-value $)$ & $\begin{array}{l}\text { Total m-water bond } \\
\text { strength }(\mathrm{Sc}) \mathrm{kcal} / \mathrm{mol}\end{array}$ & $\begin{array}{l}\text { Bond strength without } \\
\text { LPE }(\mathrm{Sc}) \mathrm{kcal} / \mathrm{mol}\end{array}$ & $\begin{array}{l}\text { Total m-water bond } \\
\text { strength }(\mathrm{Y}) \mathrm{kcal} / \mathrm{mol}\end{array}$ & $\begin{array}{l}\text { Bond strength without } \\
\text { LPE }(\mathrm{Y}) \mathrm{kcal} / \mathrm{mol}\end{array}$ \\
\hline $\mathrm{pCH}(-0.17)$ & -16.35 & -7.61 & -20.87 & -17.34 \\
$\mathrm{pCN}(1.0)$ & -16.00 & -8.11 & -21.56 & -17.84 \\
$\mathrm{pF}(0.062)$ & -15.90 & -7.88 & -21.02 & -17.57 \\
$\mathrm{H}(0.0)$ & -16.36 & -7.74 & -20.98 & -17.49 \\
$\mathrm{pNO}_{2}(0.778)$ & -16.90 & -8.22 & -21.54 & -17.99 \\
$\mathrm{pOCH}_{3}(-0.268)$ & -19.31 & -7.51 & -20.78 & -17.23 \\
$\mathrm{pBr}(0.232)$ & -15.77 & -7.83 & -21.02 & -17.56 \\
$\mathrm{pCl}(0.227)$ & -17.79 & -7.86 & -21.02 & -17.56 \\
$\mathrm{mBr}(0.391)$ & -16.27 & -7.70 & -21.63 & -17.66 \\
$\mathrm{mCH}(-0.069)$ & -16.87 & -7.62 & -21.35 & -17.41 \\
$\mathrm{mCl}(0.373)$ & -17.88 & -7.69 & -21.57 & -17.66 \\
$\mathrm{mCN}(0.56)$ & -17.19 & -8.71 & -22.15 & -18.38 \\
$\mathrm{mF}(0.337)_{\mathrm{mNO}_{2}(0.71)}^{-16.44}$ & -8.46 & -21.46 & -17.58 \\
$\mathrm{mOCH}_{3}(-0.16)$ & -20.39 & -9.90 & -27.37 & -19.76 \\
& -18.01 & -8.14 & -21.81 & -17.92 \\
\hline
\end{tabular}

Table 4. Calculated Isotropic ${ }^{17} \mathrm{O}$ NMR for bound water oxygen

\begin{tabular}{|c|c|c|c|c|}
\hline Substituent & $\begin{array}{l}\text { Calculated }{ }^{17} \mathrm{O} \text { NMR } \\
\text { water oxygen }(\mathrm{Sc})\end{array}$ & $\begin{array}{l}\text { Difference from no } \\
\text { substitution }(\mathrm{H})\end{array}$ & $\begin{array}{l}\text { Calculated }{ }^{17} \mathrm{O} \text { NMR } \\
\text { water oxygen }(\mathrm{Y})\end{array}$ & $\begin{array}{l}\text { Difference from no } \\
\text { substitution }(\mathrm{H})\end{array}$ \\
\hline $\mathrm{pCH}_{3}(-0.17)$ & 62.61 & -0.20 & 39.67 & -0.23 \\
\hline $\mathrm{pCN}(1.0)$ & 62.68 & -0.12 & 40.48 & 0.58 \\
\hline $\mathrm{pF}(0.062)$ & 62.79 & -0.01 & 40.17 & 0.27 \\
\hline $\mathrm{H}(0.0)$ & 62.81 & 0.00 & 39.90 & 0.00 \\
\hline $\mathrm{pNO}_{2}(0.778)$ & 62.51 & -0.29 & 40.55 & 0.65 \\
\hline $\mathrm{pOCH}_{3}(-0.268)$ & 62.03 & -0.78 & 39.34 & -0.56 \\
\hline $\mathrm{pBr}(0.232)$ & 62.62 & -0.19 & 40.06 & 0.16 \\
\hline $\mathrm{pCl}(0.227)$ & 62.67 & -0.14 & 40.11 & 0.21 \\
\hline $\mathrm{mBr}(0.391)$ & 66.21 & 3.40 & 40.45 & 0.55 \\
\hline $\mathrm{mCH}_{3}(-0.069)$ & 65.79 & 2.98 & 40.79 & 0.89 \\
\hline $\mathrm{mCl}(0.373)$ & 66.28 & 3.48 & 40.16 & 0.16 \\
\hline $\mathrm{mCN}(0.56)$ & 61.18 & -1.63 & 40.43 & 0.53 \\
\hline $\mathrm{mF}(0.337)$ & 66.24 & -3.44 & 40.03 & -0.13 \\
\hline $\mathrm{mNO}_{2}(0.71)$ & 61.20 & 1.60 & 39.40 & 0.49 \\
\hline $\mathrm{mOCH}_{3}(-0.16)$ & 67.32 & -4.51 & 41.26 & -1.36 \\
\hline
\end{tabular}

\subsection{Calculated ${ }^{17} \mathrm{O}$ NMR of Bound Water}

The bond strength between the water and the central metal ion should be altered according to the electron density of the ligand and the metal ion. This electron density will be reflected in the shielding of the water oxygen nucleus. Shielding can be calculated using quantum mechanics, with the differences reflected in the reported values (Table 4). While ${ }^{1} \mathrm{H}$ NMR is the most commonly used method to track the bound water, we used ${ }^{17} \mathrm{O}$ NMR. The water exchange rate with respect to substitution pattern can be inferred (Aime et al., 1998; Dunand et al., 2000; Yazyev and Helm, 2008).

For purposes of comparing changes in shielding as a result a result of $\mathrm{CT}$ interactions according to the substituent, the Hammett Constant was again employed. If the shielding of the oxygen is being affected, which should reflect the change in bond strength, there should be a correlation with the Hammett Constant value for each substituent (Fig. 11). Figure 11 shows that although the shielding can be altered by the substituent attached, there is virtually no correlation with the Hammett Constant value for each substituent evaluated.

\section{CONCLUSION}

The relationship between water exchange and the electronic properties of the ligand is complex. CT interactions from the modified pendant arm are possible, as seen from the separated pendant arm data. Electronwithdrawing groups show a reduced charge on the 
chelating oxygen, causing it to become more positive. Conversely, the electron-donating groups show an increased charge on the chelating oxygen, causing it to become more negative. However, the overall effect of these CT interactions becomes diluted because of compensation from the other coordinating oxygens. When compared to the positive slope of the coordinating oxygen from a plot of charge vs. Hammett Constant with respect to the pendant arm (Fig. 6-8), the remaining coordinating oxygens have a negative slope. These data indicate that remaining coordinating oxygens have a negative slope, which suggests that remaining coordinating oxygens are contributing their own CT interactions from the modified pendant arm. These results explain why ${ }^{17} \mathrm{O}$ NMR does not show any correlation in shielding or deshielding as a result of CT interactions.

As seen in the calculation of the metal-water bond strength, the conformation of the ligand plays an important role in the strength of the metal-water bond. Therefore, in addition to compensation of charge from the chelating oxygens, the perturbation of the ligand itself when water is attached should be considered. The DOTAM ligand will go through equilibrium between (SAP) and (TSAP) conformations (Aime et al., 1994). This shift in equilibrium is accounted for by the shifts of the acetate arms, which coordinate the metal center. This shift in acetate arms will also shift the orbital overlap corresponding to the arms. This shift in orbital overlap will affect the CT interactions. Therefore, CT interactions from pendant arms are highly dependent on the orientation of the pendant arm and the resulting conformer of the contrast agent, in this case DOTAM ligand.

The effect of steric interactions, orbital overlap and charge compensation all have to be taken into account when considering the effects of the water-metal bond interactions taking place in a contrast agent. These total interactions negate the effect of the lone CT interactions as a result of the pendant arm electronics. These factors are important to consider for ligand design and all aspects of the contrast agent. Although electronics do play an important role, the overall consideration of the ligand conformation, solvent shells and other interactions with its environment need to be further investigated for contrast agent design.

\section{ACKNOWLEDGEMENT}

Thanks to the H.O. West Foundation in support of the West Center for Computational Chemistry and Drug Design. Also, the researchers from the West Center for their continued helpful discussions, in particular Dr. Zhiwei Liu and Dr. Vojislava Pophristic.

\section{REFERENCES}

Aime, S., G. Bombieri, F. Benetello and M. Botta, 1999a. A holmium complex of a macrocyclic ligand (DOTA) and its isostructural europium analogue. Acta Crystallogr, C55: 353-356. DOI: 10.1107/S0108270198014450

Aime, S., A. Barge, M. Botta, A. DeSousa and D. Parker, 1998. Direct NMR Spectroscopic Observation of a Lanthanide-Coordinated waater molecule whoes exchange rate is dependent of the conformation of the complexes. Angew. Chem. Int. Ed., 37: 26732674.

DOI: 10.1002/(SICI)15213773(19981016)37:19<2673::A ID-ANIE2673>3.0.CO;2-\#

Aime, S., J.R. Morrow, C.H. Lake and M.R. Churchill, 1994. Lanthanide (m) tetraamide macrocyclic complexes as synthetic ribonucleases: Strucutre and catalytic properties of [La(tcmc)(CF3S03)(EtOH)(CF,S03). Ang. Chem. Int. Ed. Engl., 33: 773-775. DOI: 10.1002/anie.199407731

Aime, S., M. Botta, M. Fasano and E. Terreno, 1999b. Prototropic and water-exchange processes in aqueous solutions of $\mathrm{Gd}(\mathrm{III})$ chelates. Acct. Chem. Res., 32: 941-949. DOI: 10.1021/ar/970300u

Becke, A.D., 1993. A new mixing of hartree-fock and local density-functional theories. J. Chem. Phys., 98: 1372-1372. DOI: 10.1063/1.464304

Benetollo, F., G. Bombieri, L. Calabi, S. Aime and M. Botta, 2003. Structural variations across the lanthanide series of macrocyclic DOTA complexes: Insights into the design of contrast agents for magnetic resonance imaging. Inorg. Chem., 42: 148157. DOI: $10.1021 / \mathrm{ic} 025790 \mathrm{n}$

Campanelli, A.R., A. Domenicano and F. Ramondo, 2003. Electronegativity, resonance and steric effects and the structure of monosubstituted benzene rings: An ab initio MO study. J. Phys. Chem. A, 107: 6429-6440. DOI: 10.1021/jp030031r

Caravan, P., A.V. Astashkin and A.M. Raitisimring, 2003. The Gadolinium(III)-water hydrogen distance in MRI contrast agents. Inorg. Chem., 42: 39723974. DOI: $10.1021 /$ ic034414f

Caravan, P., J.J. Ellison, T.J. McMurray and R.B. Lauffer, 1999. Gadolinium (III) Chelates as MRI contrast agents: Structure, dynamics and applications. Chem. Rev., 99: 2293-2352. DOI: $10.1021 / \mathrm{cr} 980440 \mathrm{x}$ 
Consentino, U., D. Pitea, G. Moro, V. Barone and A. Villa et al., 2004. Theoretical investigation into the influence of conformational equilibria on the waterexchange process in magnetic resonance imaging contrast agents. Theor. Chem Acc., 111: 204-209. DOI: $10.1007 / \mathrm{s} 00214-003-0525-4$

Dunand, F.A., S. Aime and A.E. Merbach, 2000. First $17 \mathrm{O}$ NMR observation of coordinated water on both isomers of $[\mathrm{Eu}(\mathrm{DOTAM})(\mathrm{H} 2 \mathrm{O})] 3+$ : A direct access to water exchange and its role in the isomerization. J. Am. Chem. Soc., 122: 1506-1512. DOI: $10.1021 / \mathrm{ja} 993204 \mathrm{~s}$

Dunning, T.H. Jr. and P.J. Huzinaga, 1976. Modern Theoretical Chemistry. 1st Edn., New York.

Elango, M., R. Parthasarathi, G.K. Narayanan, A. Sabeelullah and U. Sarkar et al., 2005. Relationship between electrophilicity index, Hammett constant and nucleus-independent chemical shift. J. Chem. Sci., 117: 61-65. DOI: 10.1007/BF02704362

Frisch, M., 2004. Gaussian03. Gaussian, Inc.: Wallingford CT.

Furet, E., K. Costuas, P. Rabiller and O. Maury, 2008. On the sensitivity of $\mathrm{f}$ electrons to their chemical environment. J. Am. Chem. Soc., 130: 2180-2183. DOI: $10.1021 / \mathrm{ja} 073224 \mathrm{r}$

Glendening, E.D., J.K. Badenhoop, A.E. Reed, J.E. Carpenter and J.A. Bohmann et al., 2001. Theoretical Chemistry Institute. University of Wisconsin.

Gross, K. and P.G. Seybold, 2001. Comparison of quantum chemical parameters and hammett constants in correlating $\mathrm{pKa}$ values of substituted anilines. J. Org. Chem., 66: 6919-6925. DOI: $10.1021 /$ jo010234g

Gung, B.W., Y. Zou, Z. Xu, J.C. Amicangelo and D.G. Irwin et al., 2008. quantitative study of interactions between oxygen lone pair and aromatic rings: Substituent effect and the importance of closeness of contact. J. Org. Chem., 73: 689-693. DOI: 10.1021/jo702170j

Hammett, L.P., 1937. The effect of structure upon the reactions of organic compounds. benzene derivatives. J. Am. Chem. Soc., 59: 96-103. DOI: 10.1021/ja01280a022

Hay, P.J. and W.R. Wadt, 1985a. Ab initio effective core potentials for molecular calculations: Potentials for the transition metal atoms Sc to Hg. J. Chem. Phys., 82: 270-283. DOI: 10.1063/1.448799
Hay, P.J. and W.R. Wadt, 1985b. Ab initio effective core potentials for molecular calculations. Potentials for $\mathrm{K}$ to $\mathrm{Au}$ including the outermost core orbitals. J. Chem. Phys., 82: 299-299. DOI: 10.1063/1.448975

Hollingsworth, C.A., P.G. Seybold and C.M. Hadad, 2002. Substituent effects on the electronic structure and pKa of benzoic acid. Int. J. Quant. Chem., 90: 1396-1403. DOI: 10.1002/qua.10362

Ilieva, S., B. Hadjieva and B. Galabov, 2002. Theory supplemented by experiment. electronic effects on the rotational stability of the amide group in psubstitued acetanilides. J. Org. Chem., 67: 62106215. DOI: 10.1021/jo025791x

Kotex, J., J. Rudovsky, P. Herman and I. Lukes, 2006. Three in One: TSA, TSA' and SA units in one crystal structure of a yttrium(III) complex with a monophosphinated H4dota analogue. Inorg. Chem., 45: 3097-3102. DOI: 10.1021/ic060006a

Kumar, K., C.A. Chang, L.C. Francesconi, D.D. Dischino and M.F. Malley et al., 1994. Synthesis, stability and structure of gadolinium (III) and yttrium (III) macrocyclic poly (amino carboxylates). Inorg. Chem., 33: 3567-3575. DOI: 10.1021/ic00094a021

Lau, E.Y., F.C. Lightstone and M.E. Colvin, 2006. Environmental effects on the structure of metal ionDOTA complexes: An ab initio study of radiopharmaceutical metals. Inorg. Chem., 45: 92259232. DOI: 10.1021/ic0602897

Lauffer, R.E., 1987. Paramagnetic metal complexes as water proton relaxation agents for NMR imaging theory and design chemical. Review, 87: 901-927. DOI: $10.1021 / \mathrm{cr} 00081 \mathrm{a} 003$

Lee, C., W. Yang and R.G. Parr, 1988. Development of the Colle-Salvetti correlation-energy formula into a functional of the electron density. Phys. Rev., 37: 785-789. DOI: 10.1103/PhysRevB.37.785

Muller, G., S.D. Kean, D.P. James and P. Riehl, 2002. Temperature and pressure dependence of excitation spectra as a probe of the solution structure and equilibrium theromdynamics of a Eu(III) complex containing a modified DOTA Ligand. J. Phys. Chem., 106: 12349-12355. DOI: 10.1021/jp021747

Parker, D., H.P. Andrei, S. Batsanov and K. Senanayke, 2003. Structure analysis of nine-coordinate lanthanide complexes: Steric control of the metalwater distance across the series. Inorg. Chem., 42: 8646-8651. DOI: $10.1021 /$ ic030203z 
Pratt, D.A., G.A. Dilabio, P. Mulder and K.U. Ingold, 2004. Bond strengths of toluenes, anilines and phenols: To hammett or not. Acc. Chem. Res., 37: 334-340. DOI: 10.1021/ar010010k

Reed, A.E., F. Weinhold and L.A. Curtiss, 1988. Intermolecular interactions from a natural bond orbital, donor-acceptor. Chem. Rev., 88: 899-899. DOI: $10.1021 / \mathrm{cr} 00088 \mathrm{a} 005$

Sinnokrot, M.O. and C.D. Sherrill, 2003. Unexpected substituent effects in face-to-face $\pi$-stacking interactions. J. Phys. Chem. A, 107: 8377-8379. DOI: $10.1021 / \mathrm{jp} 030880 \mathrm{e}$

Stoppioni, P. and M.D. Vaira, 2002. Theoretical investigation on the geometries of DOTA and DOTA-like complexes and on the transition states of their conformational equilibria. New J. Chem., 26: 136-144. DOI: 10.1039/B106168M

Wadt, W.R. and P.J. Hay, 1985. Ab initio effective core potentials for molecular calculations: Potentials for $\mathrm{K}$ to $\mathrm{Au}$ including the outermost core orbitals. J. Chem. Phys., 82: 284-284. DOI: 10.1063/1.448975

Weinhold, F., 1998. Natural Bond Orbital Mehtods. In: Encyclopedia of Computational Chemistry, Schleyer, P.V.R., N.L. Allinger, T. Clark, J. Gasteiger and P.A. Kollman et al. (Eds.), Wiley, ISBN-10: 047196588X, pp: 3580-3580.
Woods, M., D.E. Woessner and A.D. Sherry, 2009. Paramagnetic lanthanide complexes as PARACEST agents for medical imaging. Chem. Soc. Rev., 35: 500-511. DOI: 10.1039/b509907m

Woods, M., Z. Kovacs, S. Zhang and A.D. Sherry, 2003. Towards the rational design of magnetic resonance imaging contrast agents: Isolation of the two coordination isomers of lanthanide DOTA-type complexes. Angew. Chem. Int. Ed., 42: 5889-5892. DOI: 10.1002/anie.200352234

Yazyev, O.V. and L. Helm, 2008. Nuclear spin relaxation parameters of MRI contrast agents-insight from quantum mechanical calculations. Eur. J. Inorg. Chem., 2008: 201-211. DOI: 10.1002/ejic.200701013

Yurieva, A.G., O.K. Poleschuk and V.D. Filimonov, 2008. Comparative analysis of a full-electron basis set and pseudopotential for the iodine atom in DFT quantum-chemical calculations of iodine-contianing compounds. J. Struct. Chem., 49: 548-552. DOI: 10.1007/s10947-008-0073-9

Zhang, S., K. Wu and A.D. Sherry, 2002. Unusually sharp dependence of water exchange rate versus lanthanide ionic radii for a series of tetramide complexes. J. Am. Chem. Soc., 124: 4226-4227. DOI: $10.1021 / j a 017133 k$ 